\title{
A comunicação no contexto do acolhimento em uma unidade de saúde da família de São Carlos, SP
}

\author{
Adriano de Oliveira ${ }^{1}$ \\ João Carneiro da Silva Neto ${ }^{2}$ \\ Maria Lúcia Teixeira Machado ${ }^{3}$ \\ Mariza Borges Brito de Souza ${ }^{4}$ \\ Adriana Barbieri Feliciano ${ }^{5}$ \\ Márcia Niituma Ogata ${ }^{6}$
}

OLIVEIRA, A. et al. Communication within the context of user welcoming into a family health unit in São Carlos, São Paulo. Interface - Comunic., Saúde, Educ., v.12, n.27, p.749-62, out./dez. 2008.

One of the sustaining pillars of user welcoming strategies is the relationship between the players involved. This paper aimed to understand the perceptions of workers and users of a family health unit regarding the role of communication within the context of user welcoming and to develop educational actions to enable reflection and discussion on the topic. A qualitative approach was used, with an action-research design. Data were gathered through participant observation and semi-structured interviews. Five categories emerged from the analysis, relating to: communication concepts, bonding, qualified listening, commitment and collective spaces. During the educational activities, the users expressed their expectations of having qualified professionals available for welcoming and problem-solving listening, and the workers indicated that the team's professional commitment level was fundamental. The path proposed is to optimize the existing spaces through giving value to discussions on relational matters like communication.

Key words: User welcoming. Communication. Family health.
Um dos pilares que sustenta a estratégia do acolhimento é a relação entre os atores envolvidos. Este trabalho teve como objetivos compreender as percepções de trabalhadores e usuários de uma unidade de saúde da família sobre o papel da comunicação no contexto do acolhimento, e desenvolver ações educativas que permitissem reflexão e discussão sobre o tema. Utilizamos uma abordagem qualitativa, na modalidade pesquisa-ação. Realizamos a coleta de dados mediante observação participante e entrevista semiestruturada. Da análise emergiram cinco categorias: concepções de comunicação, criação do vínculo, escuta qualificada, comprometimento e espaços coletivos. Nas ações educativas realizadas, os usuários explicitaram sua expectativa de contar com profissionais qualificados para uma escuta acolhedora e resolutiva, e os trabalhadores apontaram como fundamental o nível de comprometimento profissional da equipe. Propomos como um caminho a otimização dos espaços existentes por meio da valorização de discussões sobre aspectos relacionais, tal como a comunicação.

Palavras-chave: Acolhimento. Comunicação. Saúde da Família.

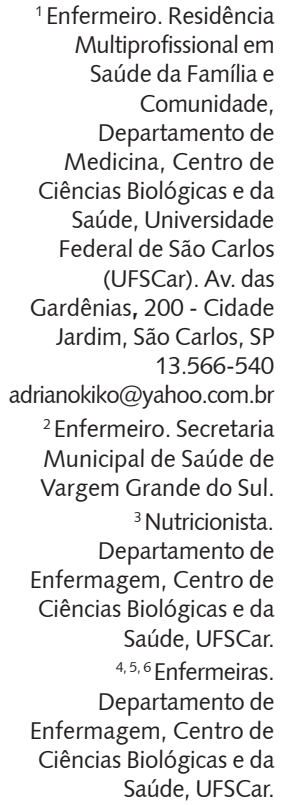

${ }^{1}$ Enfermeiro. Residência Multiprofissional em Saúde da Família e Comunidade, Departamento de Medicina, Centro de Ciências Biológicas e da Saúde, Universidade Federal de São Carlos (UFSCar). Av. das Gardênias, 200 - Cidade Jardim, São Carlos, SP 13.566-540 adrianokiko@yahoo.com.br ${ }^{2}$ Enfermeiro. Secretaria Municipal de Saúde de Vargem Grande do Sul. ${ }^{3}$ Nutricionista. Departamento de Enfermagem, Centro de Ciências Biológicas e da Saúde, UFSCar. 4,5,6 Enfermeiras. Departamento de Enfermagem, Centro de Ciências Biológicas e da Saúde, UFSCar. 
Ainda que eu falasse a língua dos homens e dos anjos, se não tivesse amor, seria como o metal que soa

ou como o sino que tine.

(I Coríntios 13:1)

\section{Entendendo as ferramentas}

O Programa de Saúde da Família (PSF) foi lançado pelo Ministério da Saúde em 1994, que desde a década anterior já experimentava, em algumas regiões, empreitadas menos abrangentes, porém bemsucedidas, tendo como principal exemplo o programa de agentes comunitários de saúde (PACS). Atualmente, preconiza-se o uso do termo Estratégia de Saúde da Família (ESF), um símbolo que circunscreve a maior parte dos princípios que constituem o Sistema Único de Saúde (SUS). Dentre tais princípios, talvez um dos mais significantes seja a integralidade, que desloca o eixo da atenção às doenças ou partes do indivíduo, tratando-o por especialidades restritivas, para o desafio de entender o indivíduo em sua totalidade, englobando todas as suas necessidades.

Ainda persiste, em nossas práticas, o modelo hegemônico de atenção à saúde médico-centrado, o que se configura como grande entrave da humanização em saúde.

Assim, a questão da vida vai sendo progressivamente reduzida à análise do funcionamento das várias partes de órgãos do corpo. [...] Cada vez mais a medicina torna-se a ciência das doenças. A vida globalmente entendida deixa de ser sua preocupação [...] A prioridade é buscar instrumentos para atacar cada uma das doenças e não estratégias de fortalecimento do organismo como um todo ou do grupo social em que essas doenças ocorrem [...].

(Vasconcelos, 2006, p.279)

O sobrepujar desse modelo demanda esforços em dois sentidos. Tanto ao colocar em pauta a importância do trabalho integrado de todos os membros da equipe de saúde, quanto ao formatar um desenho organizativo centrado nas relações (Teixeira, 2003).

O acolhimento chega nesse contexto como uma estratégia para redefinir a lógica do processo de trabalho em saúde, criando um campo fértil para mudanças. Faz parte de uma ampla proposta de humanização da atenção à saúde consolidada pela política HumanizaSUS. Entendemos acolhimento como

um modo de operar os processos de trabalho em saúde de forma a atender a todos que procuram os serviços de saúde, ouvindo suas solicitações e assumindo no serviço uma postura capaz de acolher, escutar e pactuar respostas mais adequadas aos usuários. Implica prestar um atendimento com resolutividade e responsabilização. (Brasil, 2006, p.21)

Um dos pilares que sustenta ou concede viabilidade à proposta do acolhimento é a maneira como se dão as relações entre os diversos atores envolvidos. "Essa proposta de acolhimento se apóia no reconhecimento das relações entre as pessoas no momento do atendimento como uma das questõeschave, e em especial a relação trabalhador-usuário" (Matumoto, 2002, p.2).

O autor também aponta que "na construção das relações entre o serviço e usuários, entre trabalhadores e usuários a comunicação é um dos aspectos fundamentais para este entendimento de acolhimento" (Matumoto, 2002, p.1).

E de que tipo de comunicação estamos falando quando nos voltamos ao nosso interesse no contexto do acolhimento? Referimo-nos à capacidade de diálogo entre trabalhadores da saúde e destes com os usuários, na intenção de construir, de maneira co-responsável, um serviço resolutivo que atenda as necessidades de todos esses atores, bem como relações que produzam ou fortaleçam a autonomia dos usuários.

Todavia, não é comum encontrarmos um campo fértil para o desenvolvimento de habilidades de comunicação, devido à própria lógica dos serviços, ou seja, a configuração do processo de trabalho. "A 
organização do trabalho não favorece o estabelecimento de relações saudáveis, não promove diálogos francos para que se possa esclarecer quaisquer desentendimentos, que ocorram durante o processo de produção do trabalho em saúde" (Matumoto, 2002, p.3).

Não obstante, não se pode negar a responsabilidade que cada trabalhador possui na superação dos fatores limitantes que se apresentam, empreendendo esforços para construir alternativas dentro do contexto de sua realidade. Referindo-se novamente às dificuldades e procurando vislumbrar o que é possível, mesmo em situações desfavoráveis, Matumoto $(2002$, p.2) afirma: "A escuta, entretanto, pode ser acolhedora, com valorização das queixas, dispensando atenção e respeito pelo usuário, ajudando-o a percorrer o caminho da resolução de seu problema".

Para apoderar-se da comunicação como ferramenta eficiente, é preciso compreendê-la dentro de um universo determinado de interesses, uma prática que considere os diversos contextos dos sujeitos que a compõem, e seja concebida com base na perspectiva de todos estes. Nesse sentido, consideramos que a Educação possui um papel fundamental.

Não estamos nos referindo a uma noção de Educação, que ainda permanece predominante, onde apenas alguns possuem o poder por portar o conhecimento a ser transmitido àqueles que nada sabem, e estes, por sua vez, entendidos como pessoas que contavam apenas com um conhecimento não formal gerado por experiências de pouca valia (Franco, 2007).

Não pensamos em ações educativas que permitam a mera transmissão de informações com baixa chance de serem acessadas pela memória num momento em que se faça necessário. Defendemos processos de construção real de conhecimento, fundamentado em práticas do cotidiano carregadas pela subjetivação de cada indivíduo. Cotidiano que é fonte inesgotável de situações que podem se tornar disparadores de reflexão.

\footnotetext{
Entendemos que os processos educacionais só terão eficácia, se conseguirem, junto com os processos de cognição, operar mudanças também nas subjetividades dos trabalhadores. A identificação Educação Permanente em Saúde está carregando, então, a definição pedagógica para o processo educativo que coloca o cotidiano do trabalho - ou da formação - em saúde em análise, que se permeabiliza pelas relações concretas que operam realidades e que possibilita construir espaços coletivos para a reflexão e avaliação de sentido dos atos produzidos no cotidiano. (Franco, 2007, p.6)
}

Com base nessas reflexões, propusemos, como objetivos deste estudo, a compreensão e análise das percepções de trabalhadores e usuários de uma unidade de saúde da família concernentes à comunicação no contexto do acolhimento. Além de contribuir, também, para o aprofundamento da discussão, iniciando a prática de ações educativas e a construção de propostas sobre o tema.

\section{Cenário}

Localizada no centro geográfico do estado de São Paulo, São Carlos possui 216.840 habitantes e, destes, 96,05\% residem na área urbana (Fundação Seade, 2006). Destaca-se pelo seu vigor acadêmico e tecnológico, e, embora questões pertinentes à saúde não sejam seu maior foco produtivo, desde 2001 vem desenvolvendo uma série de ações integradas relevantes, marcando um período de avanços significativos.

$\mathrm{Na}$ atualidade, a ESF merece destaque na estruturação da saúde do município. A rede possui hoje 11 equipes em funcionamento, proporcionando uma cobertura que corresponde a aproximadamente $23 \%$ da população do município (São Carlos, 2007).

Em janeiro de 2007, o acolhimento foi instituído na rede básica do município no intuito de fortalecer a humanização dos serviços. Todavia, constata-se que tanto as equipes profissionais quanto a população têm tido dificuldade para se adaptarem às mudanças pertinentes a esse processo. 


\section{Preparando o solo}

Neste estudo, utilizamos a abordagem qualitativa na modalidade pesquisa-ação (Thiollent, 1987).

\section{Caracterização do local de estudo}

O trabalho foi realizado em uma unidade de saúde da família que tinha cadastradas 1.723 famílias, totalizando 6.686 pessoas (São Carlos, 2007). Recentemente, foi aprovado um projeto de reformulação da distribuição geográfica da área mediante a proposta, da secretaria de saúde, de criar uma nova unidade circunvizinha a esta. O compromisso oficial de cobertura desta equipe passou a ser de, aproximadamente, seiscentas famílias. Porém, por dificuldades operacionais, o projeto ainda não foi efetivado, permanecendo o atendimento à população não cadastrada, que na verdade constitui a maior parte do volume final de trabalho da equipe e compromete a qualidade da assistência e as relações que se travam entre trabalhadores e, destes, com os usuários.

\section{Sujeitos da pesquisa}

Buscando a sensibilização e a mobilização de toda a equipe da unidade, convidamos todos os seus integrantes a participar do processo, a saber: uma médica, uma enfermeira, duas auxiliares de enfermagem e seis agentes comunitários de saúde. Uma das auxiliares optou por não participar da pesquisa. Além dos membros da equipe, incluímos a participação de dois usuários que integram o conselho gestor local atualmente e dois outros que, embora já não sejam conselheiros, ainda são atuantes no controle social.

\section{Etapas do trabalho}

\section{Inserção no campo}

A primeira etapa teve como objetivo a construção do vínculo entre os pesquisadores/interventores, a equipe e os usuários. Realizamos a aproximação conciliando as atividades deste trabalho com o cumprimento de estágio curricular da graduação, que ocorreu entre 13/08/2007 e 05/11/2007, totalizando 125 horas presentes na unidade. Isso incluiu participação em reuniões de equipe e do conselho gestor local.

\section{Coleta e análise dos dados}

Utilizamos a entrevista semi-estruturada com profissionais e usuários, realizadas entre os meses de outubro e novembro de 2007. Todas foram gravadas e transcritas na íntegra. A observação-participante permeou todo o processo. Observamos situações como: a recepção do usuário, seu atendimento e de sua família, a resolutividade, o encaminhamento do usuário a outro profissional, e como se dá o sistema de referência e contra-referência. Tratou-se de um processo ativo, no qual não apenas observamos a atuação dos profissionais, mas participamos dos atendimentos da demanda espontânea pela lógica do acolhimento, reuniões de equipe, e demais atividades oferecidas no serviço.

Para a análise dos dados, utilizamos a técnica de Análise Categorial Temática descrita por Bardin (1977).

\section{Intervenção com a equipe e usuários}

Após a análise dos dados, havíamos planejado uma atividade com os trabalhadores e, na seqüência, com os usuários, com a pretensão de que os trabalhadores assumissem o papel de facilitadores na atividade posterior com os usuários. Em decorrência de problemas institucionais, houve um atraso na liberação do projeto por parte do Comitê de Ética em Pesquisa em Seres Humanos (CEP), o que dificultou a negociação de datas para a realização das atividades. Mediante este fato, a ordem precisou ser invertida. Realizamos a atividade na reunião do conselho gestor local e, depois, na reunião de equipe. As ações educativas foram pautadas nos preceitos da Educação Permanente em Saúde, marcadas por um modelo participativo de construção do conhecimento. 
O projeto foi aprovado pelo CEP da Universidade Federal de São Carlos (UFSCar) - Parecer 239/2007 - e pela Secretaria Municipal de Saúde de São Carlos. Todos os participantes - profissionais de saúde e usuários - receberam as informações em relação ao projeto por meio de um Termo de Consentimento Livre e Esclarecido. Assim, incluímos as participações apenas mediante autorização. Não houve conflito de interesses.

\section{Os frutos da seara}

Os resultados foram divididos em duas partes principais. Apresentamos o produto da pesquisa e, logo após, o que foi obtido nas atividades de intervenção realizadas.

\section{Pesquisa}

Identificamos os entrevistados pelas letras U (usuários) e T (trabalhadores), seguidos de numeração para diferenciá-los. Com base na análise das entrevistas, emergiram cinco categorias temáticas:

- O momento do encontro: a criação do vínculo.

- Como me comunicar?

- Atenção à diversidade: a escuta qualificada.

- Co-responsabilidade.

. Espaço de trocas e construções coletivas.

\section{O momento do encontro: a criação do vínculo}

Entende-se, como encontro, o momento em que o usuário, movido por qualquer que seja sua necessidade (biológica, emocional ou espiritual), se encontra com o profissional ao procurar o serviço buscando a solução para o seu problema. Com base nessa definição, anuímos com Onocko Campos (2005, p.575) quando ela lembra "que o usuário sempre comparece a esse encontro movido por demandas mais ou menos explícitas, munido de seu corpo e sua singular subjetividade".

As conseqüências desse primeiro encontro alteram de forma decisiva a passagem do usuário pela unidade e a resolução do seu problema. Nesse sentido, segundo Campos (1997), o vínculo com os usuários do serviço de saúde amplia a eficácia das ações de saúde e favorece a participação do usuário na produção do seu cuidado. No fim, essa observação entra em consonância com a fala de um dos usuários ao apontar que: "se o usuário, ele é bem atendido, bem acolhido, consegue se expressar e ser atendido, facilita o diálogo" (U1).

Outro usuário cita a necessidade do resgate da auto-estima da pessoa que procura a unidade: "não precisa melá muito, mas um bom dia, boa tarde, acho que vai levantá mais o astral [...] Quando a pessoa te pergunta o que tá acontecendo, aí já vai, cria um elo de comunicação melhor pra pessoa, já levanta" (U2).

Vemos, assim, a importância do primeiro encontro entre usuário e profissional, e, nesse sentido, o valor que atribuímos ao acolhimento e à geração de vínculo.

Contudo, a consolidação da estratégia do acolhimento e a valorização do vínculo se fazem necessárias tanto entre profissionais quanto entre os usuários, pois eles ainda o concebem como um "procedimento" que deve ser realizado por um profissional ou categoria específica: "infelizmente o acolhimento ali não é aquela pessoa que fique constante [...] tem essa variação, essa troca, cada dia é um agente que fica (responsável pelo acolhimento)" (U1); "eu acho que a enfermagem. Acho que diretamente a enfermagem [deve realizar o acolhimento]" (T7).

\section{Como me comunicar?}

A comunicação é um processo que acontece entre as pessoas, no qual se devem considerar todas as experiências, culturas, valores, interesses e expectativas, pois ela nos capacita para entendermos o mundo, transformando-o e, ao mesmo tempo, sendo transformados por ele (Silva, 2005).

Teixeira (1997) nos lembra que o "modelo unilateral" que desconsidera o usuário enquanto sujeito ainda está presente nas práticas em saúde, comprovado pela manutenção das relações de poder e distanciamento. 
Para alguns profissionais e usuários, a comunicação deve ser trabalhada entre todos os atores envolvidos nas práticas de saúde, de forma franca e objetiva, visando a criação de vínculo por meio de uma escuta empática, tendo como objeto final um atendimento resolutivo para o usuário: $\mathrm{A}$ comunicação deve ser "franca, direta, objetiva, muito singular, muita humildade, muito respeito" (U1); "o papel da comunicação é dar resolutividade ao problema! Então, através dessa comunicação, através de coleta de dados que resulte em resolutividade" (T5).

Além disso, afirmam que a comunicação não deve se restringir a momentos formais, como as reuniões de equipe ou as consultas: "Não que eu ache que a comunicação é uma coisa que tá assim, ligada a um tempo pré-fixado dentro de uma reunião, não é isso. Acho que isso é uma coisa que acontece o dia todo, toda hora, a hora que você encontra com o usuário, com o funcionário" (T9).

Ao mesmo tempo, atribuem à comunicação a possibilidade de fornecer à equipe informações sobre os problemas mais freqüentes da comunidade, e, a partir daí, elaborarem os diagnósticos, as intervenções, e demais estratégias necessárias para a solução dos problemas:
Conhecer melhor os problemas, o que surge, os que estão mais visíveis, os que estão mais latentes na população. Acho que essa comunicação ajudaria assim, não só uma pessoa, mas ajudaria toda a equipe a ter uma visão do que acontece de verdade, o quê que está acontecendo de verdade na nossa comunidade [...] não só conhecer o diagnóstico, mas também você atuar em cima daquilo que você diagnosticou. (T3)

Um dos trabalhadores também aponta a necessidade de capacitação da equipe, pois, embora reconheça o papel da comunicação nas relações de trabalho, não consegue utilizar-se dela como considera necessário, o que acaba comprometendo a confiança das orientações dos profissionais frente aos usuários: "a comunicação fica meio distorcida, até mesmo por essa falta de cursos, falta de maior esclarecimento para o funcionário. O quê que é? Do papel da comunicação [...] Eu creio que a equipe não tá muito esclarecida do papel da comunicação" (T3). Outro trabalhador acrescenta: "se a comunicação entre a equipe não tá coesa, tá fragmentada, tem ruído, tem percepções diferentes, a hora que você vai trabalhar com a comunidade acaba transparecendo prá comunidade [...] E aí a comunidade também fica confusa, com medo" (T9).

Notamos que a diferença entre as posturas adotadas pelos profissionais contribui para a geração de ruídos. O que pretendemos aqui não é defender a idéia de homogeneizar as formas de pensar e expressar-se, perdendo, com isso, a riqueza da diversidade, mas que as diferentes características converjam para a construção de relações melhores. "Todo mundo sabe alguma coisa e ninguém sabe tudo, e a arte da conversa não é homogeneizar os sentidos fazendo desaparecer as divergências, mas fazer emergir o sentido no ponto de convergência das diversidades" (Teixeira, 2003, p.105).

Os discursos revelam que a equipe como um todo tem enfrentado muitas dificuldades em utilizar a comunicação. Um trabalhador nos lembra que o enfrentamento é uma situação que a maioria das pessoas evita: "Então, uma coisinha que podia ser resolvida tão facilmente com uma conversa 'olha, você fez isso errado, tal', mas acaba virando uma bola de neve. Por quê? Porque ninguém chega e fala: "vamos conversar'" (T5).

Na mesma direção, concordamos com Fillipini et al., quando se referem à habilidade dos profissionais, afirmando que ela não deve se restringir apenas à comunicação verbal: "necessidade de sensibilidade dos profissionais para executarem os cuidados, observando as manifestações verbais e não-verbais do cliente" (Fillipini, 2006, p.73).

Pois, como lembra Silva apud Edwards (2005, p.28) "apenas 7\% dos pensamentos (e intenções) são transmitidos por palavras e [...] 55\% são transmitidos pelos sinais do corpo".

Silva (2005) também traz um entendimento com o qual concordamos, ao afirmar que a relação entre trabalhador e usuário deve ser planejada na comunicação empática, no sentido de compreender e respeitar as percepções do outro em relação à vida. 


\section{Atenção à diversidade: a escuta qualificada}

Discutindo sobre eqüidade e associando a integralidade, encontramos publicação do Ministério da Saúde, que refere ser importante no momento do encontro entre profissional e usuário:

o resgate da integralidade do cliente, percebido como sujeito participante nas ações de saúde, implicando no reconhecimento de sua subjetividade em interação com o profissional que o atende. Acolher o saber e o sentir do cliente, por meio de uma 'escuta ativa', é condição básica para um atendimento de qualidade. (Brasil, 1997, p.4)

Para alguns profissionais entrevistados, a resolutividade dos problemas assinalados pelos usuários pode vir a ser comprometida por conta da subjetividade presente em cada caso: "A população é assim [...] uma mistura de cultura, socioeconômica [...] eu acho que é um pouco complicado. Eles não entendem muito, entendeu? Não é muito esclarecido. As vezes você fala uma coisa, duas, três, quatro, cinco vezes" (T7).

A gente percebe que há muita procura do paciente [...] é porque ou ele não explicou muito bem o que ele realmente queria de uma vez só, porque ele volta várias vezes [...] ou a gente não fez as perguntas certas pra tirar dele a resposta [...] eu acho que em relação a nossa comunicação com eles não tem sido suficiente. (T6)

Nesse sentido, buscando deixar mais claro o que seria 'escuta ativa' - uma vez que ela foi interpretada por nós como uma das alternativas para os problemas levantados tanto pelos profissionais, quanto pelos usuários - trazemos a idéia de Durães-Pereira et al. apud Mariotti (2007, p.466) de que a escuta "pode ser construída como um processo transparente, através de uma rede de conversação em que abrimos questões, compartilhamos aspirações, questionamos e aprendemos, interagimos com o todo e buscamos a pluralidade de idéias"; e de Filgueira e Deslandes $(1999$, p.124) endossando que a "atitude de escuta pressupõe a capacidade do profissional de propiciar um espaço para que o usuário possa expressar aquilo que sabe, pensa e sente em relação a sua situação de saúde e responder às reais expectativas, dúvidas e necessidades deste".

Essas observações convergem com as falas apresentadas por alguns dos usuários: "se [...] não houver aquele contato com respeito, com educação, com simplicidade pra tratar do mais humilde até o mais bem informado, isso deixa o próprio usuário meio constrangido" (U1); "No meu caso, eu sou mais fechado, mas quando as pessoas chegam 'um bom dia, um boa tarde, um aperto de mão' já me abre. Eu já nasci assim, com esse tipo fechado, mas eu me abro também" (U2).

A não criação de um espaço onde aconteça esta escuta qualificada faz com que um mesmo usuário retorne mais vezes à unidade, ao mesmo tempo em que esses retornos os deixam mais 'nervosos', conforme apresentado na fala de um usuário:

Porque às vezes o usuário chega nervoso e saí nervoso e entra mais estressado ainda pra falar com médico. Então acho que o papel do acolhimento é aquele de preparar a pessoa, ver o que ele tem, o que ele precisa, qual o problema dele, quem pode ajudar ele [...] pra você montar as informações que possam ajudar, tanto nos cuidados no caso da enfermagem, como o médico também. (U1)

A escuta precisa ocorrer de forma que propicie resolutividade no atendimento. Partilhamos das idéias de Schimith e Lima apud Carvalho e Campos (2004, p.1487) quando afirmam que o "acolhimento é um arranjo tecnológico que busca garantir acesso aos usuários com o objetivo de escutar todos os pacientes, resolver os problemas mais simples e/ou referenciá-los se necessário".

Sendo assim, é preciso mudar a forma com que os trabalhadores da saúde têm sido formados, como se fossem componentes que já devam possuir um leque de habilidades inatas e, portanto, não demandam capacitação (Ceccim, 2004). 
Como vimos anteriormente, é necessário difundir, entre os profissionais, um "olhar" mais apurado para os valores e crenças de cada usuário (subjetividade). Então, a educação permanente torna-se ferramenta importante, pois, por meio da valorização de seus próprios saberes, crenças e habilidades, o profissional transforma-se em agente ativo no processo de trabalho. Sua aprendizagem torna-se significativa, pois reconhece que suas demandas são realmente pertinentes (Filgueiras, Deslandes, 1999).

\section{Co-responsabilidade}

Aqui discutimos o que poderíamos chamar de responsabilidade coletiva. Essa pode ser promovida por meio de processos comunicacionais eficientes, construindo uma rede de influência que provoque um movimento de formação de determinada harmonia nos níveis de envolvimento e comprometimento de todos os interessados em promover saúde.

Esse é um traço que foi apontado tanto por trabalhadores como por usuários. Houve consenso de que a disposição e comprometimento de apenas um dos segmentos não são suficientes para construir o tipo de relação que se quer. "O compromisso profissional e os direitos dos usuários são faces complementares e interdependentes deste mesmo processo de melhoria da qualidade do atendimento" (Camelo et al., 2000, p.36). "Se a gente quiser exigir das duas partes, não adianta chegar um usuário lá todo dedicado, todo respeitoso e o atendente mal fala com ele, mal tentar entender o que ele quer" (U1).

Camelo et al. (2000, p.36) nos trazem também uma proposta de qual seria o papel de cada um nessa relação:
A construção de uma relação de ajuda entre o profissional e o cliente depende de ambos. $O$ profissional deve saber administrar a situação, apresentando comportamentos de acolhida, verbais e não-verbais. O usuário deve demonstrar disponibilidade interna e envolvimento durante o relacionamento, participando da busca de ações possíveis para a resolução de seus problemas ou satisfação de seus desejos e necessidades.

Ao pautarmos esses aspectos, estamos, sobretudo, nos remetendo à promoção da autonomia, um elemento essencial sem o qual não é possível gerar co-responsabilidade. Normalmente, os indivíduos só assumem uma postura ativa a partir do momento em que se entendem como sujeitos no processo, portadores de direitos e potencial para contribuir.

É muito comum observar usuários apontando as falhas dos profissionais e vice-versa, estabelecendose o hábito de culpabilização do outro, o que pode gerar uma enganosa sensação de nunca ser participante na causa dos problemas e, portanto, não se sentir responsável em promover as mudanças necessárias. Referindo-se à realidade vivenciada naquela unidade, outro usuário curiosamente expressou o seguinte: "os profissionais estão se comunicando bem com a gente, tão procurando. A gente vê interesse de se comunicar bem, de se integrar a todo mundo. O mais difícil mesmo são os usuários. Eles só querem vir na hora da precisão" (U4).

Os profissionais não foram capazes de apresentar uma autocrítica semelhante. As falas ressaltam o entendimento de que, por vezes, a falta de envolvimento por parte dos usuários é que reflete um estado de desinteresse dos profissionais. Complementamos afirmando que o contrário também é válido, estabelecendo-se um ciclo danoso ao processo de produção do cuidado. Franco e Merhy (2005) apresentam os benefícios que podem ser produzidos quando se consegue romper com esse ciclo e desenvolver um comprometimento mútuo:

O vínculo dos usuários com a equipe, tendo a responsabilização desta para com o cuidado àqueles, cria referências seguras e, sobretudo, a forte idéia de 'empoderamento' dos usuários, que se dá por processos de aprendizagem de como se cuidar e também processos de subjetivação que fazem com que eles se sintam com condições, competentes e aptos a se cuidar. (Franco, Merhy, 2005, p.187) 


\title{
Espaços de trocas e construções coletivas
}

Muito se discute sobre a promoção de educação em saúde como prática que pode ocorrer em todo momento e lugar. Concordamos com essa idéia, mas reforçamos que os encontros, mesmo que sem horário e local estabelecidos, devem ser munidos de reflexão e busca de conhecimento. Podendo, inclusive, esta prática ser considerada essencial para o entendimento das necessidades da clientela.

\begin{abstract}
Esse diálogo se orienta pela busca de maior conhecimento das necessidades de que o usuário se faz portador e dos modos de satisfazê-las [...] a pautar todas as práticas de conhecimento que são dão em serviço 'todas as formas de conversa, individuais ou em grupo, em que, de alguma forma, se pesquisa alguma coisa'. (Teixeira, 2003, p.103)
\end{abstract}

A troca de idéias em espaços informais foi apontada, pela maior parte dos entrevistados, como um fator bem-sucedido neste serviço, mas destacamos que o campo da informalidade não consegue dar conta de todas as necessidades de trocas de uma equipe de saúde.

Ao pensarmos em como se encontra o estabelecimento de espaços de troca organizados entre os próprios trabalhadores, percebemos algumas preocupações. A maneira de organizar o atendimento da demanda espontânea é um fator que tem sido desafiador para os membros da equipe. A maioria demonstra despreparo e referem a necessidade de se estabelecerem momentos de trocas para discutirem a questão de maneira específica.

a própria equipe, cada um tem seu conceito de acolhimento, mas a gente não troca esse conceitos, essas percepções, sentimentos [...] falta um espaço onde a gente discuta isso formalmente, onde a gente diga assim: 'Vamos discutir agora o acolhimento'. (T9)

A dificuldade não se faz presente apenas ao se discutir a formatação do processo de trabalho em geral, mas, também, envolve alguns detalhes sobre sua operacionalidade. Novamente, evidencia-se a importância da qualidade da comunicação entre os membros da equipe.

por exemplo, passa um recado prá uma ou às vezes não dá tempo de reunir todo mundo, entendeu? Aí não passa prá outra [...] a outra não tá sabendo [...] Não sei se às vezes pelo tempo ou porque você não tá na unidade ou não dá pra reunir, entendeu? (T7)

O profissional enfermeiro ainda possui o simbolismo daquele a quem se atribui o dever de capacitar os demais elementos da equipe. $E$ isso tem sido muito cobrado deste profissional neste momento de transição do tipo de processo de trabalho que agora é pautado pelo acolhimento: "os agentes se sentem despreparados, a enfermeira, ela nem sempre tem esse tempo de tá conversando com a gente o papel do acolhimento" (T3).

Nos diálogos estabelecidos com a enfermeira, e ao observar suas ações no cotidiano, podemos retratar a causa da dificuldade em cumprir esse papel educativo esperado:

o enfermeiro está preso às ações instituídas da gestão, capturado por normas, com ações centradas nas ações programáticas, com pouca flexibilidade na geração de propostas instituintes na construção do processo do cuidado integral, na criação de espaços de poder compartilhado, que dificulta a aprendizagem significativa no trabalho, para o compromisso, a responsabilização e autonomia no processo de cuidar. (Andrade et al., 2007, p.1)

As mesmas autoras sugerem formas de enfrentamento do problema:

É necessário rever concepções de liderança e gestão na formação de enfermeiros, permear a integralidade no redirecionamento do cuidado de enfermagem e utilizar da educação 
permanente como potente ferramenta na mudança de processos de trabalho. (Andrade et al., 2007, p.1)

Vale ressaltar que tal responsabilidade não deve recair sobre os ombros de um único profissional, pois cada um possui um papel em relação ao próprio desenvolvimento e da equipe como um todo, tal como discutimos na categoria "co-responsabilidade". No mérito do que está em pauta, um dos avanços mais significativos que a equipe alcançou recentemente foi o estabelecimento da 'reunião de estudo de caso', projetada para ser realizada todas as semanas.

Ah, eu acho que é mais aquela reunião, de casos lá, que a gente discute o quê que aconteceu [...] que o pessoal fez no acolhimento, em algum caso que não passou pela $\mathrm{Dr}^{\mathrm{a}}$ e ficou pra resolver depois. Acho que é o momento que mais acontece as discussões. (T4)

Todavia, constatamos que, após algum tempo, a atividade foi suspensa por dificuldade de conciliação de horários entre todos os profissionais, e as discussões para retomar essa iniciativa permanecem. Talvez o espaço de maior relevância atualmente seja mesmo a típica reunião de equipe. Porém esta também tem apresentado muitas limitações de diversas naturezas: "A gente não consegue reunir toda a equipe de uma vez só. Nas nossas reuniões sempre tem alguém faltando (T6); No meu caso se eu falo alguma coisa eu sou sempre apedrejada [...] sempre aponto as coisas e já fui até crucificada por agir assim, então eu não falo mais nada hoje em dia". (T8).

Alguns identificam a necessidade de fazer da reunião um espaço para a construção de propostas sólidas de resolução de problemas e planejamento de ações coletivas. Essa é uma preocupação importante, uma vez que há o risco de que esses espaços tornem-se apenas verdadeiros 'muros de lamentação': "A gente realmente tem que discutir e traçar metas que a gente queira alcançar dentro desse contexto" (T9).

Outro tema muito discutido por diversos autores e que surgiu nas entrevistas é a constituição de espaços que promovam a integração entre equipe e usuários na construção do modelo de atenção. Pudemos perceber que os profissionais entendem essa importância, mas ainda não conseguem articularse de forma a efetivá-lo: “Então a gente não tem essa rede de comunicação dentro da equipe e da equipe com a comunidade de uma maneira efetiva, que faça com que a gente entenda realmente $o$ quê que tá acontecendo e monte um processo que seja eficaz [...] Falta criar espaços pra que essa comunicação aconteça" (T9).

Algumas iniciativas da equipe têm buscado a criação de espaços de discussão e troca de idéias com usuários. Isso tem contribuído para melhorar as relações da equipe com a população, mas ainda está longe de ser o suficiente para o estabelecimento de uma gestão participativa e controle social efetivo.

\section{Intervenção}

Desde a concepção deste trabalho, entendíamos que seria importante executar alguma ação que pudesse contribuir para o aprimoramento do tema pesquisado junto à equipe. De forma planejada, pautando-nos na perspectiva da educação permanente, desenvolvemos a pesquisa referente a um aspecto crítico do processo de trabalho da equipe, de forma que pudesse se tornar um disparador de reflexão da prática. Portanto, essa atividade educativa segue tal lógica, propondo um espaço de expressão das idéias referidas individualmente nas entrevistas e objetivando proporcionar trocas e discussões propositivas. O modelo operacional da atividade garantiu os princípios da roda, co-gestão e interventores no papel de facilitadores.

Assim, com base na análise do produto das entrevistas na atividade com os usuários, criamos tarjetas não nomeadas, com resumos das principais idéias passíveis de discussão e relacionadas ao tema 
proposto. Os quatro usuários entrevistados estavam presentes, cada um dirigia-se ao quadro fixado na parede, sorteava aleatoriamente uma tarjeta, e tecia comentários a respeito. A atividade inteira foi permeada por estratégias lúdicas, aguçando os sentidos e incentivando a ação reflexiva.

Ao final, propusemos a criação de novas tarjetas contendo sugestões para resolução dos problemas discutidos. Nelas encontramos:

- Intensificar de forma globalizada o acolhimento: usuário x unidade de saúde - "Comunicação, atendimento, retorno e satisfação no que faz";

- Atender todas as pessoas com o mesmo respeito e atenção que você gostaria de ter recebido;

- Gente que entenda da profissão para que tenha sucesso, ou seja, que seja melhor para o povo;

- Realizando as reuniões e conversando para trazer outros usuários;

- Queremos espaço para reuniões, de preferência, em lugar que todos escutem com atenção.

Os usuários explicitam sua expectativa de contar com profissionais qualificados para uma escuta atenciosa e resolutiva, além do fortalecimento dos espaços de encontro. O fato de haver apenas um profissional presente na atividade com os usuários causou a sensação de que não haveria continuidade das discussões relacionadas ao tema devido ao término de nossa atuação na unidade. Realçamos essa preocupação durante a intervenção realizada com os profissionais.

$\mathrm{Na}$ atividade desenvolvida no espaço de uma reunião de equipe, oito profissionais estavam presentes, e se deu numa dinâmica muito semelhante à que realizamos no conselho gestor. Destacamos apenas que, antes de propormos a criação das novas tarjetas, apresentamos algumas diretrizes do Ministério da Saúde segundo a cartilha: "O acolhimento como rede de conversações diretriz e dispositivo da Política Nacional de Humanização da Atenção e Gestão do SUS" (Abbes, 2006). As propostas que surgiram nas novas tarjetas trouxeram o seguinte:

- Trabalho em equipe;

. Comprometimento e atitude;

- Maior comprometimento de toda a equipe, e melhor reconhecimento da área. Falar a mesma língua;

. Comprometimento com os planos de serviços propostos e com as pessoas que são atendidas;

. Partilhando experiências. Comprometimento dos membros com a equipe e usuários;

. Empatia;

. Comprometimento. Responsabilidade e relacionamento entre a equipe;

- Ser capacitado e trabalhar em equipe.

Uma vez que o comprometimento e trabalho em equipe foram elementos recorrentes nas propostas, mas abordados de maneira superficial e inespecífica, propusemos o preenchimento de um instrumento, para que os profissionais pudessem expressar, de forma mais concreta, o que entendem sobre os termos e a que se dispõem nesse sentido. Seis deles se propuseram a responder, e abaixo segue a síntese do que foi apresentado:

. Os conceitos são complementares.

- Ter responsabilidade.

- Respeitar os usuários e colegas de profissão.

. Não só dividir o trabalho, mas somar experiências.

. O trabalho precisa ter significação para os profissionais.

É possível notar que os trabalhadores restringiram-se em expressar somente seu entendimento sobre os termos. Apenas um trabalhador lançou uma proposta: a possibilidade de momentos de reflexão sobre os objetivos individuais e coletivos do trabalho como forma de construir a significação do mesmo para todos os trabalhadores.

Por solicitação da equipe, ao final da intervenção, montamos um mural com todas as tarjetas produzidas por eles nas atividades citadas acima e fixamos na sala de reuniões. Buscando proporcionar um momento avaliativo, nos propusemos levar-Ihes uma apresentação da análise dos resultados da pesquisa, e aguardamos, deles, um agendamento. 


\section{A colheita com olhos para o futuro}

Para concluir, trazemos uma síntese referente à aprendizagem alcançada, por meio da análise dos resultados obtidos na pesquisa e com o que foi construído nas atividades educativas desenvolvidas.

A criação de vínculo é fundamental para se desenvolver uma relação de confiança que leve o usuário a aderir às ações de saúde propostas, e, mais que isso, para envolvê-lo de maneira ativa em seu próprio cuidado. E isso começa a se constituir a partir do primeiro momento de encontro.

Para que a comunicação favoreça esse processo, é preciso zelar por alguns princípios, tais como: respeito, sinceridade e empatia. A competência comunicacional, que não é inata, demanda aprendizagem permanente e precisa ser afinada entre todos os membros da equipe, como uma orquestra. E se efetivada com qualidade, pode potencializar o planejamento e ações do serviço.

A comunicação envolve não só a capacidade de se fazer claro, mas, sobretudo, de escutar o outro de forma acolhedora. Para sensibilizar e mobilizar os indivíduos é preciso atingir sua subjetividade, não apenas conceder-Ihes informação proporcionando um entendimento conceitual.

Para avançar na busca por esse ideal de relacionamento, é necessário romper com a prática de culpabilização do outro e repensar a conduta no sentido de todos assumirem a responsabilidade de promover transformações.

A consolidação destas propostas acontece a cada momento de troca travado no cotidiano, mas os avanços mais significativos têm sido percebidos com o fortalecimento de espaços coletivos organizados, onde se preconiza mais horizontalidade nos processos de aprendizagem - considerando tanto os espaços destinados aos profissionais da equipe, quanto os de interlocução com os usuários.

A complexidade das dificuldades impostas pelo trabalho cotidiano precisa ser considerada ao discutirmos os entraves e limitações da comunicação. Despidos desta compreensão estaríamos fadados a um mero julgamento improdutivo. O que pretendemos é ressaltar que acreditamos ser possível a criação de estratégias alternativas no enfrentamento de problemas que se colocam como obstáculos para uma qualificada produção do cuidado. Isso pressupõe a utilização do potencial criativo de cada trabalhador e o envolvimento de cada usuário.

Ao final de todas as reflexões sobre a experiência vivenciada, afirmamos que os objetivos foram atingidos de forma satisfatória, por termos conseguido mais do que captar as percepções dos envolvidos sobre o tema. Como resultado, disparamos um processo de reflexão da prática dos profissionais, além de promovermos a aproximação entre os segmentos. Tanto trabalhadores quanto usuários demonstraram interesse na continuidade do processo, o que esperamos que, de fato, ocorra.

Iniciativas isoladas de apenas alguns dos atores não constituem uma força suficiente para promover as mudanças necessárias. Todavia podem se tornar exemplos disparadores do processo de melhoria das relações interpessoais, que colaborem para um serviço mais resolutivo. Apontamos, como um caminho, a otimização dos espaços já existentes por meio da valorização de discussões sobre aspectos relacionais, tal como a comunicação, preconizando o encaminhamento de propostas concretas a cada encontro.

\section{Colaboradores}

Adriano de Oliveira e João Carneiro da Silva Neto participaram de todas as etapas de planejamento, desenvolvimento e execução do trabalho e da elaboração e revisão do artigo. Maria Lúcia Teixeira Machado orientou todas as etapas de realização e avaliação do trabalho e participou da elaboração e revisão do artigo. Mariza Borges Brito de Souza co-orientou e avaliou o trabalho e participou da elaboração do artigo. Adriana Barbieri Feliciano e Márcia Niituma Ogata colaboraram na realização e avaliação do trabalho e na elaboração do artigo. 


\section{Referências}

ABBÊS, C. O acolhimento como rede de conversações: diretriz e dispositivo da política nacional de humanização da atenção e gestão do SUS. Brasília: Ministério da Saúde, Secretaria de Atenção a Saúde, 2006.

ANDRADE, C.S. et al. O enfermeiro no trabalho em equipe no cuidado da família. 2006. Disponível em: <http://www.uesc.br/atencaoasaude/trabalhos/

o_enfermeiro_no_trabalho_em_equipe_no_cuidado_da_familia.pdf $>$. Acesso em: 23 ab̄r. 2007.

BARDIN, L. Análise de conteúdo. Lisboa: Edições 70, 1977.

BRASIL. Ministério da Saúde. Secretaria de Atenção à Saúde. Núcleo Técnico da Política Nacional de Humanização. Acolhimento nas práticas de produção de saúde. 2.ed. Brasília: Ministério da Saúde, 2006.

Ministério da Saúde. Secretaria de Políticas de Saúde. Coordenação Nacional de DST e Aids. Aconselhamento em DST, HIV e Aids. Brasília, 1997 (Série B - Textos Básicos de Saúde).

CAMELO, S.H.H. et al. Acolhimento à clientela: estudo em unidades básicas de saúde no município de Ribeirão Preto. Rev. Latino-am. Enferm., v.8, n.4, p.30-7, 2000.

CAMPOS, G.W.S. Consideração sobre a arte e a ciência da mudança: a revolução das coisas e reforma das pessoas. O caso da saúde. In: CECÍlIO, L.C.O. (Org.). Inventando a mudança na saúde. 2.ed. São Paulo: Hucitec, 1997. p.29-87.

CECCIM, R.B. Educação permanente em saúde: desafio ambicioso e necessário. Interface - Comunic., Saúde, Educ., v.9, n.16, p.161-77, 2004.

DURÃES-PEREIRA, M.B.B.B.; NOVO, N.F.; ARMOND, J.E. A escuta e o diálogo na assistência ao pré-natal, na periferia da zona sul, no município de São Paulo. Ciênc. Saúde Coletiva, v.12, n.2, p.465-76, 2007.

FILGUEIRAS, S.L.; DESLANDES, S.F. Avaliação das ações de aconselhamento: análise de uma perspectiva de prevenção centrada na pessoa. Cad. Saúde Pública, v.15, supl.2, p.121-31, 1999.

FILLIPINI, R. Relacionamento enfermeiro, paciente e família: fatores comportamentais associados à qualidade da assistência. Arq. Méd. ABC, v.31, n.2, p.73-7, 2006.

FRANCO, T.B. Produção do cuidado e produção pedagógica: integração de cenários do sistema de saúde no Brasil. Interface - Comunic., Saúde, Educ., v.11, n.23, p.427-38, 2007.

FRANCO, T.B.; MERHY, E.E. A produção imaginária da demanda e o processo de trabalho em saúde. In: PINHEIRO, R.; MATTOS, R.A. (Orgs.). Construção social da demanda: direito à saúde, trabalho em equipe, participação e espaços públicos. Rio de Janeiro: CEPESC/UERJ - ABRASCO, 2005. p.181-94.

FUNDAÇÃO SEADE. Perfil municipal de São Carlos. Disponível em: <http:// www.seade.gov.br/produtos/perfil/perfil.php>. Acesso em: 22 ago. 2007.

MATUMOTO, S. et al. A comunicação como ferramenta para o acolhimento em unidades de saúde. In: SIMPÓSIO BRASILEIRO DE COMUNICAÇÃO EM ENFERMAGEM, 8., 2002, São Paulo. Anais eletrônicos... Ribeirão Preto: EERP-USP, 2002. Disponível em: http://www.proceedings.scielo.br/scielo.php?script=sci_arttext\& pid=MSC0000000052002000100050\&lng=pt\&nrm=iso. Acesso em: 14 abr. 2007.

ONOCKO CAMPOS, R. O encontro trabalhador-usuário na atenção à saúde: uma contribuição da narrativa psicanalítica ao tema do sujeito na saúde coletiva. Ciênc. Saúde Coletiva, v.10, n.3, p.573-83, 2005.

SÃO CARLOS. Prefeitura Municipal. Secretaria Municipal de Saúde. Disponível em: <http://www.saocarlos.sp.gov.br >. Acesso em: 22 ago. 2007. 
SCHIMITH, M. D.; LIMA, M. A. D. S. Acolhimento e vínculo em uma equipe do Programa Saúde da Família. Cad. Saúde Pública, v.20, n.6, p.1487-94, 2004.

SILVA, M.J.P. Comunicação tem remédio. 3.ed. São Paulo: Edições Loyola, 2005.

TEIXEIRA, R.R. O acolhimento num serviço de saúde entendido como uma rede de conversações. In: PINHEIRO, R.; MATTOS, R.A. (Orgs.). Construção da integralidade: cotidiano, saberes e práticas em saúde. Rio de Janeiro: IMS-UERJ/ABRASCO, 2003. p.89-111.

Modelos comunicacionais e práticas de saúde. Interface - Comunic., Saúde, Educ., v.1, n.1, p.7-40, 1997.

THIOLLENT, M. Metodologia da pesquisa-ação. 2.ed. São Paulo: Cortez, 1987.

VASCONCELOS, E.M. Reflexões sobre o método de pesquisa utilizado. In: (Org.). Educação popular e a atenção à saúde da família. 3.ed. São Paulo: Hucitec, 2006. p.273-81.

OLIVEIRA, A. et al. La comunicación en el contexto del acogimiento en una unidad de salud de la familia de São Carlos, estado de São Paulo, Brasil. Interface - Comunic., Saúde, Educ., v.12, n.27, p.749-62, out./dez. 2008.

Uno de los pilares que sustenta la estrategia del acogimiento es la relación entre los actores envueltos. Este trabajo ha tenido como objetivos observar las percepciones de trabajadores y usuarios de una unidad de salud de la familia sobre el papel de la comunicación en el contexto del acogimiento y desarrollar acciones educativas que permitan reflexión y discusión. Utilizamos una aproximación cualitativa en la modalidad investigación-acción. Realizamos la colecta de datos a través de la observación participante y de la entrevista semi-estructurada. Del análisis emergen cinco categorías: concepciones de comunicación, creación del vínculo, escucha cualificada, comprometimiento y espacios colectivos. En las acciones educativas realizadas, los usuarios explicitaron su expectativa de contar con profesionales cualificados para una escucha acogedora. Proponemos como un camino la optimación de los espacios existentes a través de la evaluación de discusiones sobre aspectos realiconales como la comunicación.

Palabras clave: Acogimiento. Comunicación. Salud de la familia. 